\title{
Comparative epidemiology of gestational diabetes in ethnic Chinese from Shanghai birth cohort and growing up in Singapore towards healthy outcomes cohort
}

Evelyn Xiu Ling Loo ${ }^{1,2^{*}+}$, Yuqing Zhang ${ }^{3,4 \dagger}$, Qai Ven Yap ${ }^{5}$, Guoqi Yu ${ }^{3}$, Shu E Soh ${ }^{2}$, See Ling Loy ${ }^{1,6,7}$, Hui Xing Lau ${ }^{1}$, Shiao-Yng Chan ${ }^{1,8}$, Lynette Pei-Chi Shek ${ }^{2}$, Zhong-Cheng Luo ${ }^{3,9}$, Fabian Kok Peng Yap ${ }^{7,10,11}$, Kok Hian Tan ${ }^{12}$, Yap Seng Chong ${ }^{1,8}$, Jun Zhang ${ }^{3,13+}$ and Johan Gunnar Eriksson 1,8,14,15†

\begin{abstract}
Background: Gestational diabetes mellitus (GDM) has been associated with adverse health outcomes for mothers and offspring. Prevalence of GDM differs by country/region due to ethnicity, lifestyle and diagnostic criteria. We compared GDM rates and risk factors in two Asian cohorts using the 1999 WHO and the International Association of Diabetes and Pregnancy Study Groups (IADPSG) criteria.

Methods: The Shanghai Birth Cohort (SBC) and the Growing Up in Singapore Towards healthy Outcomes (GUSTO) cohort are prospective birth cohorts. Information on sociodemographic characteristics and medical history were collected from interviewer-administered questionnaires. Participants underwent a 2-h 75-g oral glucose tolerance test at 24-28 weeks gestation. Logistic regressions were performed.

Results: Using the 1999 WHO criteria, the prevalence of GDM was higher in GUSTO (20.8\%) compared to SBC (16.6\%) $(p=0.046)$. Family history of hypertension and alcohol consumption were associated with higher odds of GDM in SBC than in GUSTO cohort while obesity was associated with higher odds of GDM in GUSTO. Using the IADPSG criteria, the prevalence of GDM was $14.3 \%$ in SBC versus $12.0 \%$ in GUSTO. A history of GDM was associated with higher odds of GDM in GUSTO than in SBC, while being overweight, alcohol consumption and family history of diabetes were associated with higher odds of GDM in SBC.
\end{abstract}

Conclusions: We observed several differential risk factors of GDM among ethnic Chinese women living in Shanghai and Singapore. These findings might be due to heterogeneity of GDM reflected in diagnostic criteria as well as in unmeasured genetic, lifestyle and environmental factors.

\footnotetext{
* Correspondence: evelyn_loo@sics.a-star.edu.sg

${ }^{\dagger}$ Evelyn Xiu Ling Loo and Yuqing Zhang are joint first authors.

†Jun Zhang and Johan Gunnar Eriksson are joint senior authors.

'Singapore Institute for Clinical Sciences (SICS), Agency for Science,

Technology and Research (A*STAR), 30 Medical Drive, Singapore 117609,

Singapore

${ }^{2}$ Department of Paediatrics, Yong Loo Lin School of Medicine, National

University of Singapore, Singapore, Singapore

Full list of author information is available at the end of the article
}

(c) The Author(s). 2021 Open Access This article is licensed under a Creative Commons Attribution 4.0 International License, which permits use, sharing, adaptation, distribution and reproduction in any medium or format, as long as you give appropriate credit to the original author(s) and the source, provide a link to the Creative Commons licence, and indicate if changes were made. The images or other third party material in this article are included in the article's Creative Commons licence, unless indicated otherwise in a credit line to the material. If material is not included in the article's Creative Commons licence and your intended use is not permitted by statutory regulation or exceeds the permitted use, you will need to obtain permission directly from the copyright holder. To view a copy of this licence, visit http://creativecommons.org/licenses/by/4.0/. The Creative Commons Public Domain Dedication waiver (http://creativecommons.org/publicdomain/zero/1.0/) applies to the data made available in this article, unless otherwise stated in a credit line to the data. 
Keywords: Asian, Gestational diabetes mellitus, International Association of Diabetes and Pregnancy Study Groups, World Health Organisation, GUSTO, Shanghai birth cohort

\section{Background}

The Developmental Origins of Health and Disease $(\mathrm{DoHaD})$ hypothesis states that exposure to environmental and lifestyle factors during critical window periods in the prenatal, perinatal and early postnatal phases influences the subsequent development of noncommunicable diseases in the offspring [1]. Pregnancy is among the most important periods of development, which can be complicated by gestational diabetes mellitus (GDM) characterized by glucose intolerance with the first recognition during pregnancy [2], complicating about $14 \%$ of pregnancies globally [3].

GDM has been associated with adverse health outcomes for both mother and child [4]; women with GDM are at increased risk of developing type 2 diabetes mellitus [5], cardiovascular diseases [6] and renal diseases [7] later in life. The hyperglycemic intrauterine environment in GDM has been found to increase the risk of fetal macrosomia and associated fetal complications such as shoulder dystocia, hyperinsulinemia and neonatal morbidities [8]. In addition, babies born to women with GDM have a greater propensity to develop type 2 diabetes mellitus and obesity later in life. These findings highlight the importance of evaluating risk factors and deriving strategies to prevent and treat GDM which may induce epigenetic modifications in utero [9].

Established risk factors for GDM include a previous pregnancy with GDM [10], pre-pregnancy overweight and obesity [11, 12], excessive gestational weight gain [12, 13], advanced maternal age [14], family history of diabetes [14], infant sex, alcohol consumption, family history of hypertension, parity and smoking [15]. Maternal weight gain in early pregnancy that disproportionately consists of increased fat deposition could impact on subsequent maternal insulin resistance [13].

There are global differences in the prevalence of GDM which varies from pooled prevalence of $5.4 \%$ to $11.5 \%$ in meta-analyses of studies from Europe and Asia, respectively $[16,17]$ due to differences in factors such as diagnostic criteria, ethnicity, lifestyle, and environmental factors. Given the differences in GDM prevalence between Shanghai and Singapore $[18,19]$ as well as varying lifestyle and environmental exposures, we sought to compare the rates and risk factors of GDM in two contemporary Asian Chinese cohorts, the Shanghai Birth Cohort (SBC) and the Growing Up in Singapore Towards healthy Outcomes cohort (GUSTO).

\section{Methods \\ Study design and population \\ Shanghai birth cohort}

The Shanghai Birth Cohort (SBC) recruited pregnant mothers who sought prenatal care at six obstetric care hospitals in Shanghai, from 2013-2016. Couples who were at least 20 years old, comprised of at least one registered Shanghai resident, intended to obtain prenatal care and deliver at hospitals involved in SBC, lived in Shanghai for at least 2 years and were willing to be involved in the study for at least 2 years were invited to participate [20]. The study protocol was approved by the ethics committee of Shanghai Xinhua Hospital (XHECC-2013-001, approved on 7 January 2013) and all participating hospitals. All methods were performed in accordance with the approved guidelines and regulations. All participants gave a written informed consent. In this study, we randomly sampled 1000 out of 3692 participants of Chinese ethnicity who were not receiving chemotherapy or psychotropic drugs from the SBC for comparisons to Chinese participants in the GUSTO cohort so that the selected cohort size is comparable to the GUSTO cohort size.

\section{GUSTO cohort}

The Growing Up in Singapore Towards healthy Outcomes (GUSTO) cohort study recruited pregnant women attending their first-trimester antenatal dating ultrasound scan clinics at two major public maternity units in Singapore, KK Women's and Children's Hospital and National University Hospital from June 2009 to September 2010. Pregnant women aged 18 years and above, from any one of the three major ethnic groups (Chinese, Malay and Indian), who were Singapore citizens or permanent residents and had the intention of delivering in either hospital as well as staying in Singapore for at least the next 5 years, and who had agreed to donate their birth tissues were invited to participate. Women who had type 1 diabetes mellitus, or who were receiving chemotherapy or psychotropic drugs were excluded. Information on sociodemographic characteristics and medical history were collected from interviewer administered questionnaires [21]. The study protocol was approved by the ethics committees of the hospitals involved: SingHealth Centralized Institutional Review Board (2018/2767, approved on 2 March 2019) and the National Healthcare Group Domain Specific Review Board (D/2009/021, approved on 26 February 2009) in Singapore. All methods were performed in accordance 
with the approved guidelines and regulations. All participants gave written informed consent. In this study, only GUSTO participants of Chinese ethnicity (out of 1247 subjects) were included in the analysis.

\section{Subject follow up and assessment of maternal blood glucose concentrations}

Participants from SBC were followed up at the recruitment visit ( $\leq 17$ weeks) and at $24-26$ weeks gestation. Questionnaires were administered to collect information on demographics, socio-economic status, lifestyle, obstetric and medical history [20]. Pre-pregnancy weight was self-reported while weight at early pregnancy was measured in the prenatal care clinic. Early pregnancy in $\mathrm{SBC}$ was defined as gestational age $\leq 17$ weeks so as to include all women who received their first antenatal care in the hospital. Participants underwent a 75-g oral glucose tolerance test (OGTT) at 24-28 weeks' gestation; fasting (FG), 1-h plasma glucose (1hPG) and 2-h plasma glucose (2hPG) concentrations were obtained using automated biochemical analyzer Hitachi LABOSPECT 008. Information on weight and length of the infant at birth was obtained from hospital medical records.

Participants from GUSTO were followed up at the recruitment visit ( $<14$ weeks) and at 24-28 weeks of gestation when questionnaires were administered to collect information on demographics, socio-economic status, lifestyle, obstetric and medical history [21]. Prepregnancy weight was self-reported while weight at early pregnancy was obtained from case notes. Participants underwent a 75-g OGTT at 24-28 weeks' gestation; overnight fasting $(8-10 \mathrm{~h})$ and 2 -h postprandial blood specimens were collected. Colorimetry [Advia 2400 Chemistry system (Siemens Medical Solutions Diagnostics) and Beckman LX20 Pro analyzer (Beckman Coulter)] was used to measure both fasting and 2-h postprandial plasma glucose concentrations. Information on weight and length of the infant at birth obtained from hospital medical records.

Plasma glucose concentrations were used to classify GDM according to the $1999 \mathrm{WHO}$ criteria: $\geq 7.0 \mathrm{mmol} / \mathrm{L}$ for FPG and/or $\geq 7.8 \mathrm{mmol} / \mathrm{L}$ for $2 \mathrm{hPG}$ in the 2 -h 75 -g OGTT, and the International Association of Diabetes and Pregnancy Study Groups (IADPSG) criteria: if any one of the plasma glucose values was at or above the following thresholds: $5.1 \mathrm{mmol} / \mathrm{L}$ for $\mathrm{FPG}, 10.0 \mathrm{mmol} / \mathrm{L}$ $1 \mathrm{hPG}$ and $8.5 \mathrm{mmol} / \mathrm{L}$ for $2 \mathrm{hPG}$. Pre-pregnancy body mass index $\left(\mathrm{BMI} ; \mathrm{kg} / \mathrm{m}^{2}\right)$ was calculated as prepregnancy weight $(\mathrm{kg})$ divided by height ${ }^{2}\left(\mathrm{~m}^{2}\right)$ and categorized as underweight $\left(<18.5 \mathrm{~kg} / \mathrm{m}^{2}\right)$, normal weight $\left(18.5-22.9 \mathrm{~kg} / \mathrm{m}^{2}\right)$, overweight $\left(23.0-27.4 \mathrm{~kg} / \mathrm{m}^{2}\right)$ and obese $\left(\geq 27.5 \mathrm{~kg} / \mathrm{m}^{2}\right)$ [22]. Gestational weight gain (GWG) in early pregnancy was defined by weight gain from pre-pregnancy to recruitment visit.

\section{Statistical analysis}

All analyses were performed using SPSS for Windows version 26.0 (SPSS Inc., Chicago, IL, USA) with statistical significance set at 2 -sided $p<0.05$. Descriptive statistics for numerical variables were presented as mean (SD) and $n$ (\%) for categorical variables. Differences in numerical variables were assessed using 2 sample $t$-test when normality and homogeneity assumptions were satisfied; otherwise, Mann-Whitney $U$ test was used. Chi-square or Fisher exact test was used for categorical variables. Birthweight percentiles categorization was based on methods described by Mikolajczyk et al. Large and small for gestational age babies were defined $>90$ th and $<10$ th percentiles, respectively [23]. We standardized GWG in early pregnancy and its velocity ( $\mathrm{kg} /$ week) into z scores, using BMI category-specific mean and SD values derived from the corresponding study cohort [23]. Predictors of GDM were assessed in logistic regression models for each cohort separately. Interaction effects between predictors were tested in the regression models. We reported odds ratio as prospective data was collected on the prevalence of GDM. The differences across the two cohorts were compared using summarized Z-test. Further analysis was performed in GUSTO cohort by adding citizenship status into the model.

\section{Results}

\section{Comparison of demographic variables between SBC and GUSTO cohort}

After removal of subjects with late enrolment in the $\mathrm{SBC}$, with non-singleton pregnancy, of non-Chinese ethnicity and with pre-existing diabetes, there were 734 and 677 subjects left in SBC and GUSTO, respectively, in the analysis (Fig. 1). Characteristics of study participants in

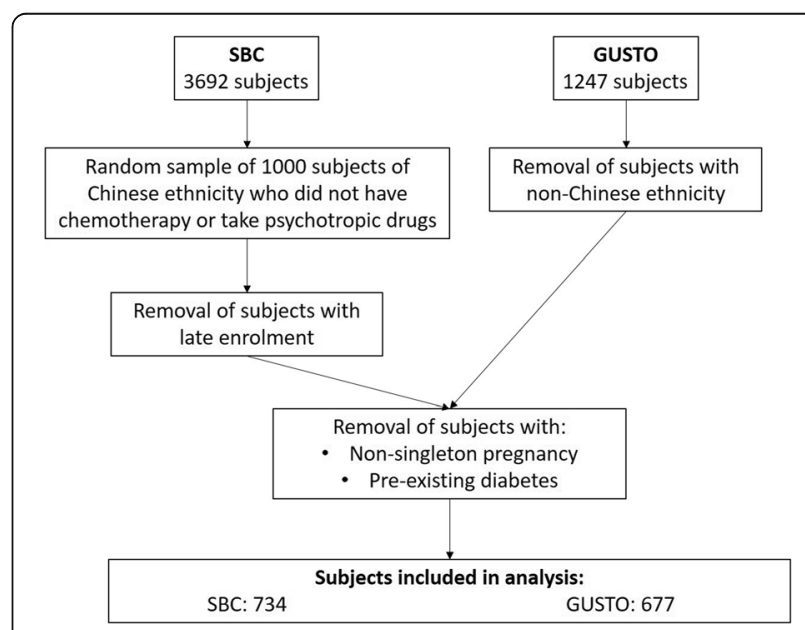

Fig. 1 Out of 1000 selected subjects from SBC and 1247 subjects in GUSTO, 734 and 677 respectively were included in the analysis after removal of subjects of non-Chinese ethnicity, with late enrolment, non-singleton pregnancy and pre-existing diabetes 
the two cohorts were presented in Table 1. GUSTO participants had lower gestational age at delivery $(38.8 \pm 1.4$ vs $39.0 \pm 1.5$ weeks, $p=0.002$ ), fasting plasma glucose concentrations $(4.3 \pm 0.4$ vs $4.4 \pm 0.4 \mathrm{mmol} / \mathrm{L}, p<0.001)$, pre-pregnancy weight $(54.5 \pm 9.5$ vs $56.6 \pm 8.7 \mathrm{~kg}, p<$ $0.001)$, weight at early pregnancy ( $56.8 \pm 10.3$ vs $59.1 \pm$ $9.4 \mathrm{~kg}, p<0.001)$, GWG during early pregnancy $(1.9 \pm$ 2.4 vs $2.5 \pm 3.2 \mathrm{~kg}, p=0.001)$, and were shorter $(159.1 \pm$ 5.6 vs $162.2 \pm 4.6 \mathrm{~cm}, p<0.001)$ and older $(32.1 \pm 4.8$ vs $29.8 \pm 3.7$ years, $p<0.001)$ compared to SBC participants.
A higher proportion of GUSTO participants consumed alcohol during pregnancy compared to SBC participants (3.3\% versus $0.3 \%$, Table 1 ), were currently smoking or had ever smoked (9.4\% versus $3.0 \%)$, had a family history of diabetes (24.4\% versus 9.2\%), had a family history of hypertension ( $41.2 \%$ versus $32.7 \%$ ), had a history of GDM in a previous pregnancy $(3.2 \%$ versus $0.4 \%)$ and had a personal history of hypertension ( $1.2 \%$ vs $0.1 \%$ ) compared to SBC participants. More GUSTO participants were parous compared to SBC participants (48.8\% versus $11.5 \%$ ).

Table 1 Characteristics of included study participants in SBC and GUSTO cohort

\begin{tabular}{|c|c|c|c|}
\hline Characteristics & $\begin{array}{l}\text { SBC } \\
(n=734)\end{array}$ & $\begin{array}{l}\text { GUSTO } \\
(n=677)\end{array}$ & $P$-value \\
\hline Maternal age & $29.8 \pm 3.7$ & $32.1 \pm 4.8$ & $<0.001$ \\
\hline Plasma glucose fasting, $\mathrm{mmol} / \mathrm{L}$ & $4.4 \pm 0.4$ & $4.3 \pm 0.4$ & $<0.001$ \\
\hline Plasma glucose $1 \mathrm{~h}, \mathrm{mmol} / \mathrm{L}$ & $7.6 \pm 1.6$ & NA & NA \\
\hline Plasma glucose $2 \mathrm{~h}, \mathrm{mmol} / \mathrm{L}$ & $6.5 \pm 1.4$ & $6.6 \pm 1.4$ & 0.143 \\
\hline Pre-pregnancy BMl, kg/m² & $21.5 \pm 3.2$ & $21.6 \pm 3.4$ & 0.637 \\
\hline BMI at early pregnancy, $\mathrm{kg} / \mathrm{m}^{2}$ & $22.5 \pm 3.4$ & $22.4 \pm 3.7$ & 0.320 \\
\hline Pre-pregnancy weight, kg & $56.6 \pm 8.7$ & $54.5 \pm 9.5$ & $<0.001$ \\
\hline Weight at early pregnancy, kg & $59.1 \pm 9.4$ & $56.8 \pm 10.3$ & $<0.001$ \\
\hline GWG at early pregnancy, kg & $2.5 \pm 3.2$ & $1.9 \pm 2.4$ & 0.001 \\
\hline GWG velocity at early pregnancy, kg/week & $0.2 \pm 0.2$ & $0.2 \pm 0.2$ & 0.911 \\
\hline Height, cm & $162.2 \pm 4.6$ & $159.1 \pm 5.6$ & $<0.001$ \\
\hline Pre-pregnancy BMI $\left(\mathrm{kg} / \mathrm{m}^{2}\right)$ & & & 0.369 \\
\hline$<18.5$ (underweight) & $109(14.9 \%)$ & $82(13.5 \%)$ & \\
\hline$\geq$ to $<23$ (normal) & $436(59.4 \%)$ & $365(60.2 \%)$ & \\
\hline$\geq$ to $<27.5$ (overweight) & $154(21.0 \%)$ & $118(19.5 \%)$ & \\
\hline$\geq$ (obese) & $35(4.8 \%)$ & $41(6.8 \%)$ & \\
\hline GWG in early pregnancy (z score) & & & 0.985 \\
\hline$<-1$ & $82(11.2 \%)$ & $68(11.5 \%)$ & \\
\hline-1 to 1 & $552(75.6 \%)$ & $446(75.2 \%)$ & \\
\hline$>1$ & $96(13.2 \%)$ & $79(13.3 \%)$ & \\
\hline Alcohol consumption during pregnancy & $2(0.3 \%)$ & $21(3.3 \%)$ & $<0.001$ \\
\hline Family history of diabetes & $62(9.2 \%)$ & $165(24.4 \%)$ & $<0.001$ \\
\hline Family history of hypertension & $225(32.7 \%)$ & $279(41.2 \%)$ & 0.001 \\
\hline Current or ever smoker & $22(3.0 \%)$ & $61(9.4 \%)$ & $<0.001$ \\
\hline History of GDM in previous pregnancy & $3(0.4 \%)$ & $22(3.2 \%)$ & $<0.001$ \\
\hline Personal history of chronic hypertension & $1(0.1 \%)$ & $8(1.2 \%)$ & 0.017 \\
\hline Parous & $84(11.5 \%)$ & $316(48.8 \%)$ & $<0.001$ \\
\hline Gestational age at delivery, week & $39.0 \pm 1.5$ & $38.8 \pm 1.4$ & 0.002 \\
\hline Male fetus & $349(49.7 \%)$ & $340(52.6 \%)$ & 0.298 \\
\hline Citizenship status & NA & & NA \\
\hline Singapore Citizen born in Singapore & & $379(56.0 \%)$ & \\
\hline Converted Citizen or permanent resident & & $298(44.0 \%)$ & \\
\hline
\end{tabular}




\section{Comparison of risk factors of GDM between SBC and GUSTO cohort}

Using the 1999 WHO criteria, the prevalence of GDM was higher in GUSTO cohort (20.8\%) compared to SBC $(16.6 \%) \quad(p=0.046)$. Using the IADPSG criteria, the prevalence of GDM was $14.3 \%$ in SBC (using all three glucose time point measures) versus $12.0 \%$ in GUSTO (defined by the fasting and $2 \mathrm{~h}$ glucose data only).

\section{WHO criteria}

Using the 1999 WHO criteria in the SBC, GDM was associated with maternal age (OR 1.1, 95\% CI 1.0-1.2, $p=$ 0.020 ) and pre-pregnancy BMI (OR 1.1, 95\% CI 1.0-1.2, $p=0.028$, Table 2). Further analysis with pre-pregnancy BMI categories showed that overweight (OR 2.3, 95\% CI 1.3-3.9, $p=0.004$, Table 3) was associated with GDM. Family history of hypertension and alcohol consumption were associated with higher odds of GDM in SBC than in GUSTO cohort (Tables 2 and 3). The analysis was repeated with the use of GWG velocity $\mathrm{z}$ score and similar results were obtained (Supplementary Tables 1 and 2, Additional file 1).

In the GUSTO cohort, GDM was associated with maternal age (OR 1.09, 95\% CI 1.03-1.14, $p=0.001$ ) and pre-pregnancy BMI (OR 1.1, 95\% CI 1.0-1.2, $p=0.002$, Table 2). Further analysis with pre-pregnancy BMI categories showed that overweight (OR 1.7, 95\% CI 1.0-2.9, $p=0.047$ ) and obesity (OR 3.7, 95\% CI 1.8-7.8, $p<$ 0.001 , Table 3) were associated with GDM. Obesity was associated with higher odds of GDM in GUSTO than in SBC (Table 3). The analysis was repeated using GWG velocity $\mathrm{z}$ score and similar results were obtained
(Supplementary Tables 1 and 2, Additional file 1). GWG velocity in early pregnancy was associated with higher odds of development of GDM in GUSTO compared to SBC $(p=0.022$, Supplementary Table 1, Additional file 1).

Further analysis was performed in GUSTO cohort by adding citizenship status in the model. Using the 1999 WHO criteria, maternal age remained significantly associated with GDM (OR 1.1, 95\% CI 1.0-1.2, $p=0.003$, Supplementary Table 3, Additional file 1). Analysis with pre-pregnancy BMI categories also showed that maternal age remained significantly associated with GDM (OR 1.1, 95\% CI 1.0-1.2, p=0.003) and obesity (OR 12.2, 95\% CI 1.6-93.4, $p=0.016$, Supplementary Table 4, Additional file 1) was associated with GDM. There were no significant interactions between citizenship status and all risk factors (Supplementary Tables 3 and 4, Additional file 1). The analysis was repeated using GWG velocity $\mathrm{z}$ score and similar results were obtained (Supplementary Tables 5 and 6, Additional file 1).

\section{IADPSG criteria}

Using the IADPSG criteria in the SBC, GDM was associated with maternal age (OR 1.1, 95\% CI 1.0-1.2, $p=$ 0.046) and pre-pregnancy BMI (OR 1.14, 95\% CI 1.051.23, $p=0.001$, Table 4). Further analysis with prepregnancy BMI categories showed that overweight (OR $2.5,95 \%$ CI 1.4-4.4, $p=0.002$ ) and obesity (OR 3.6, 95\% CI 1.3-9.6, $p=0.011$, Table 5) were associated with GDM. Being overweight, having family history of diabetes and alcohol consumption were associated with higher odds of GDM in the SBC than in the GUSTO

Table 2 Associations between risk factors and GDM defined by 1999 WHO criteria in SBC and GUSTO cohort

\begin{tabular}{|c|c|c|c|c|c|c|c|c|c|}
\hline \multirow[t]{2}{*}{ GDM } & \multicolumn{2}{|c|}{$\begin{array}{l}\text { Shanghai Birth cohort } \\
\text { Unadjusted }\end{array}$} & \multicolumn{2}{|c|}{$\begin{array}{l}\text { GUSTO Birth Cohort } \\
\text { Unadjusted }\end{array}$} & \multicolumn{2}{|c|}{$\begin{array}{l}\text { Shanghai Birth cohort } \\
\text { Adjusted }\end{array}$} & \multicolumn{2}{|c|}{$\begin{array}{l}\text { GUSTO Birth Cohort } \\
\text { Adjusted }\end{array}$} & \multirow[t]{2}{*}{$\begin{array}{l}\text { P- } \\
\text { value* }\end{array}$} \\
\hline & OR $(95 \% \mathrm{Cl})$ & P-value & OR (95\% Cl) & P-value & OR $(95 \% \mathrm{Cl})$ & P-value & OR $(95 \% \mathrm{Cl})$ & P-value & \\
\hline Maternal age & $1.08(1.03-1.14)$ & 0.003 & $1.09(1.04-1.14)$ & $<0.001$ & $1.1(1.0-1.2)$ & 0.020 & $1.09(1.03-1.14)$ & 0.001 & 1.000 \\
\hline Pre-pregnancy BMI & $1.08(1.03-1.15)$ & 0.005 & $1.11(1.05-1.17)$ & $<0.001$ & $1.1(1.0-1.2)$ & 0.028 & $1.1(1.0-1.2)$ & 0.002 & 1.000 \\
\hline \multicolumn{10}{|l|}{ GWG at early pregnancy (z score) } \\
\hline$<-1$ & 1.0 & & 1.0 & & 1.0 & & 1.0 & & \\
\hline-1 to 1 & $0.96(0.52-1.78)$ & 0.894 & $1.6(0.8-3.2)$ & 0.208 & $1.0(0.5-2.2)$ & 0.955 & $1.7(0.8-3.5)$ & 0.175 & 0.189 \\
\hline$>1$ & $0.97(0.44-2.13)$ & 0.942 & $1.8(0.8-4.2)$ & 0.173 & $0.88(0.34-2.25)$ & 0.786 & $1.7(0.7-4.0)$ & 0.258 & 0.211 \\
\hline Alcohol consumption & $5.1(0.3-82.0)$ & 0.251 & $0.67(0.19-2.32)$ & 0.526 & $8.8(0.5-144.8)$ & 0.128 & $0.73(0.20-2.64)$ & 0.632 & $<0.001$ \\
\hline Family history of diabetes & $1.6(0.8-3.0)$ & 0.165 & $1.0(0.6-1.6)$ & 0.981 & $1.0(0.5-2.1)$ & 0.996 & $0.86(0.52-1.43)$ & 0.566 & 0.755 \\
\hline Family history of hypertension & $1.6(1.0-2.4)$ & 0.032 & $0.78(0.53-1.16)$ & 0.223 & $1.5(0.9-2.5)$ & 0.092 & $0.67(0.43-1.04)$ & 0.076 & 0.016 \\
\hline Current or ever smoker & $1.1(0.4-3.4)$ & 0.842 & $0.79(0.39-1.61)$ & 0.515 & $1.6(0.4-6.0)$ & 0.509 & $1.1(0.5-2.3)$ & 0.858 & 0.528 \\
\hline Parous & $1.0(0.5-1.8)$ & 1.000 & $1.2(0.8-1.7)$ & 0.470 & $0.74(0.34-1.61)$ & 0.443 & $0.97(0.64-1.49)$ & 0.893 & 0.610 \\
\hline Male fetus & $1.1(0.7-1.7)$ & 0.633 & $1.1(0.7-1.6)$ & 0.781 & $1.1(0.7-1.7)$ & 0.801 & $1.1(0.7-1.6)$ & 0.744 & 1.000 \\
\hline
\end{tabular}

Adjusted for maternal age, pre-pregnancy BMI, GWG at early pregnancy (z score), alcohol consumption, family history of diabetes, family history of hypertension, smoking status, parity, fetal sex

In the adjusted model, $74.4 \%$ of SBC subjects (546 out of 734 ) were used, $82.9 \%$ of GUSTO subjects (561 out of 677 ) were used

*P value for the difference between the two cohorts in the adjusted model 
Table 3 Effect of GWG among women of different pre-pregnancy BMI and fetal sex on GDM development defined by 1999 WHO criteria

\begin{tabular}{|c|c|c|c|c|c|c|c|c|c|}
\hline \multirow[t]{2}{*}{ GDM } & \multicolumn{2}{|c|}{$\begin{array}{l}\text { Shanghai Birth cohort } \\
\text { Unadjusted }\end{array}$} & \multicolumn{2}{|c|}{$\begin{array}{l}\text { GUSTO Birth Cohort } \\
\text { Unadjusted }\end{array}$} & \multicolumn{2}{|c|}{$\begin{array}{l}\text { Shanghai Birth cohort } \\
\text { Adjusted }\end{array}$} & \multicolumn{2}{|c|}{$\begin{array}{l}\text { GUSTO Birth Cohort } \\
\text { Adjusted }\end{array}$} & \multirow[t]{2}{*}{$\begin{array}{l}\text { P- } \\
\text { value* }\end{array}$} \\
\hline & OR $(95 \% \mathrm{Cl})$ & P-value & OR $(95 \% \mathrm{Cl})$ & P-value & OR $(95 \% \mathrm{Cl})$ & P-value & OR $(95 \% \mathrm{Cl})$ & P-value & \\
\hline Maternal age & $1.08(1.03-1.14)$ & 0.003 & $1.09(1.04-1.14)$ & $<0.001$ & $1.1(1.0-1.2)$ & 0.014 & $1.08(1.03-1.13)$ & 0.003 & 1.000 \\
\hline GWG at early pregnancy (z score) & $0.86(0.70-1.05)$ & 0.133 & $1.2(1.0-1.5)$ & 0.085 & $0.69(0.44-1.08)$ & 0.106 & $1.2(0.8-1.7)$ & 0.444 & 0.088 \\
\hline \multicolumn{10}{|l|}{ Pre-pregnancy BMI } \\
\hline$<18.5$ & $0.72(0.37-1.39)$ & 0.324 & $0.93(0.49-1.80)$ & 0.838 & $0.85(0.38-1.90)$ & 0.687 & $1.0(0.5-2.1)$ & 0.911 & 0.785 \\
\hline$\geq 18.5$ to $<23$ & 1.0 & & 1.0 & & 1.0 & & 1.0 & & \\
\hline$\geq 23$ to $<27.5$ & $1.8(1.2-2.9)$ & 0.009 & $1.9(1.1-3.0)$ & 0.014 & $2.3(1.3-3.9)$ & 0.004 & $1.7(1.0-2.9)$ & 0.047 & 0.124 \\
\hline$\geq 27.5$ & $2.0(0.9-4.5)$ & 0.088 & $3.7(1.8-7.3)$ & $<0.001$ & $1.9(0.7-5.5)$ & 0.239 & $3.7(1.8-7.8)$ & $<0.001$ & 0.005 \\
\hline Alcohol consumption & $5.1(0.3-82.0)$ & 0.251 & $0.67(0.19-2.32)$ & 0.526 & $8.7(0.5-144.1)$ & 0.130 & $0.75(0.21-2.69)$ & 0.656 & $<0.001$ \\
\hline Family history of diabetes & $1.6(0.8-3.0)$ & 0.165 & $1.0(0.6-1.6)$ & 0.981 & $0.99(0.48-2.04)$ & 0.967 & $0.84(0.50-1.41)$ & 0.512 & 0.717 \\
\hline Family history of hypertension & $1.6(1.0-2.4)$ & 0.032 & $0.78(0.53-1.16)$ & 0.223 & $1.5(0.9-2.5)$ & 0.100 & $0.69(0.43-1.08)$ & 0.103 & 0.021 \\
\hline Current or ever smoker & $1.1(0.4-3.4)$ & 0.842 & $0.79(0.39-1.61)$ & 0.515 & $1.8(0.4-7.0)$ & 0.421 & $1.1(0.5-2.3)$ & 0.880 & 0.398 \\
\hline Parous & $1.0(0.5-1.8)$ & 1.000 & $1.2(0.8-1.7)$ & 0.470 & $0.68(0.31-1.50)$ & 0.338 & $1.0(0.7-1.6)$ & 0.880 & 0.481 \\
\hline Male fetus & $1.1(0.7-1.7)$ & 0.633 & $1.1(0.7-1.6)$ & 0.781 & $1.1(0.7-1.7)$ & 0.783 & $1.0(0.7-1.6)$ & 0.868 & 0.747 \\
\hline
\end{tabular}

Adjusted for maternal age, GWG at early pregnancy, pre-pregnancy BMI group, alcohol consumption, family history of diabetes, family history of hypertension, smoking status, parity, fetal sex

In the adjusted model, $74.4 \%$ of SBC subjects (546 out of 734) were used, $82.9 \%$ of GUSTO subjects (561 out of 677 ) were used

*P value for the difference between the two cohorts in the adjusted model

Interaction between GWG and pre pregnancy BMI group and fetal sex were included in the model but not significant

Overall interaction for GWG and pre pregnancy BMI group: $p=0.737$ for SBC, $p=0.088$ for GUSTO

Interaction for GWG and fetal sex: $p=0.254$ for SBC, $p=0.674$ for GUSTO

cohort (Tables 4 and 5). The analysis was repeated using GWG velocity $\mathrm{z}$ score and similar results were obtained (Supplementary Tables 7 and 8, Additional file 1).

In the GUSTO cohort, GDM was associated with prepregnancy BMI (OR 1.1, 95\% CI 1.0-1.2, $p=0.006$ ) and history of GDM (OR 7.7, 95\% CI 2.6-22.4, $p<0.001$, Table 4). Further analysis with pre-pregnancy BMI categories showed that obesity (OR 3.8, 95\% CI 1.7-8.8, $\mathrm{p}=0.001$, Table 5) was associated with GDM. The analysis was repeated using GWG velocity z score and similar results were obtained (Supplementary Tables 7 and 8, Additional file 1). A history of GDM was significantly associated with higher odds of GDM in the GUSTO cohort than in the SBC (Tables 4 and 5 and Supplementary Tables 7 and 8, Additional file 1).

There were no significant interactions between GWG or weight gain velocity and pre-pregnancy BMI or fetal sex in relation to the odds of GDM in SBC and GUSTO cohort (Tables 3 and 5 and Supplementary Tables 2 and 8 , Additional file 1 , all $p>0.05$ ).

Further analysis was performed in GUSTO cohort by adding citizenship status in the model. Using the IADP SG criteria, history of GDM in previous pregnancy remained significantly associated with GDM (OR 26.4, 95\% CI 2.6-269.8, $\mathrm{p}=0.006$, Supplementary Table 9, Additional file 1). Similarly, analysis using pre-pregnancy BMI categories also showed that history of GDM in previous pregnancy remained significantly associated with GDM (OR 37.1, 95\% CI 3.3-416.5, $p=0.003$ ). Obesity (OR 11.6, 95\% CI 1.3-102.4, $p=0.027$ ) was also associated with GDM (Supplementary Table 10, Additional file 1). There were no significant interactions between citizenship status and all risk factors (Supplementary Tables 9 and 10, Additional file 1). The analysis was repeated using GWG velocity $\mathrm{z}$-score and similar results were obtained (Supplementary Tables 11 and 12, Additional file 1).

\section{Preterm birth and birthweight for gestational age}

Using the 1999 WHO criteria, preterm birth rates were non-significantly higher among women with GDM $(8.3 \%)$ vs. without $(4.4 \%)$ in the SBC $(p=0.077$, Supplementary Table 13, Additional file 1 ), but were significantly higher $(12.1 \%$ vs $6.1 \%)$ in the GUSTO cohort ( $p=$ 0.018). There were no significant differences in birthweights nor the rates of small or large for gestational age births in GDM and non-GDM groups in both cohorts (Supplementary Table 13, Additional file 1).

Using the IADPSG criteria, there were no significant differences in the rates of preterm birth, large or small for gestational age births in GDM and nonGDM groups in both cohorts (Supplementary Table 14, Additional file 1). 


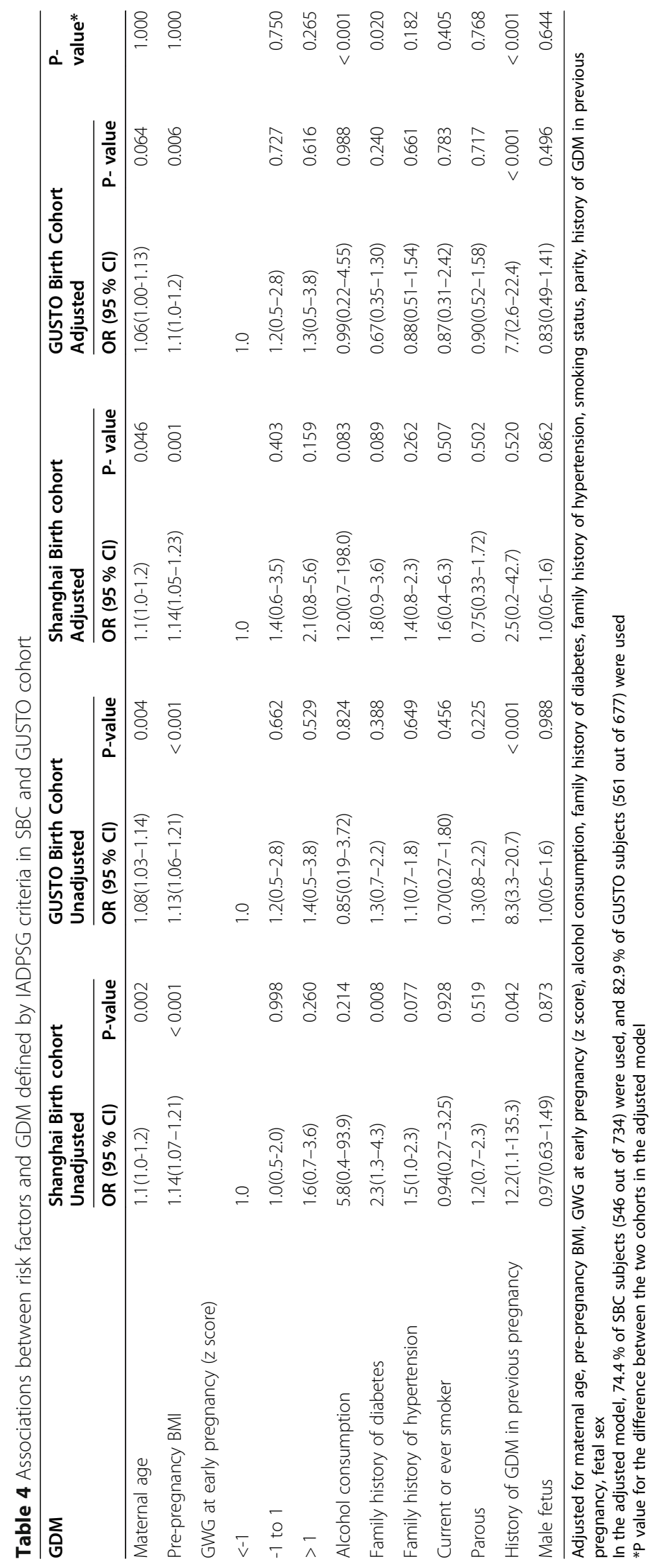




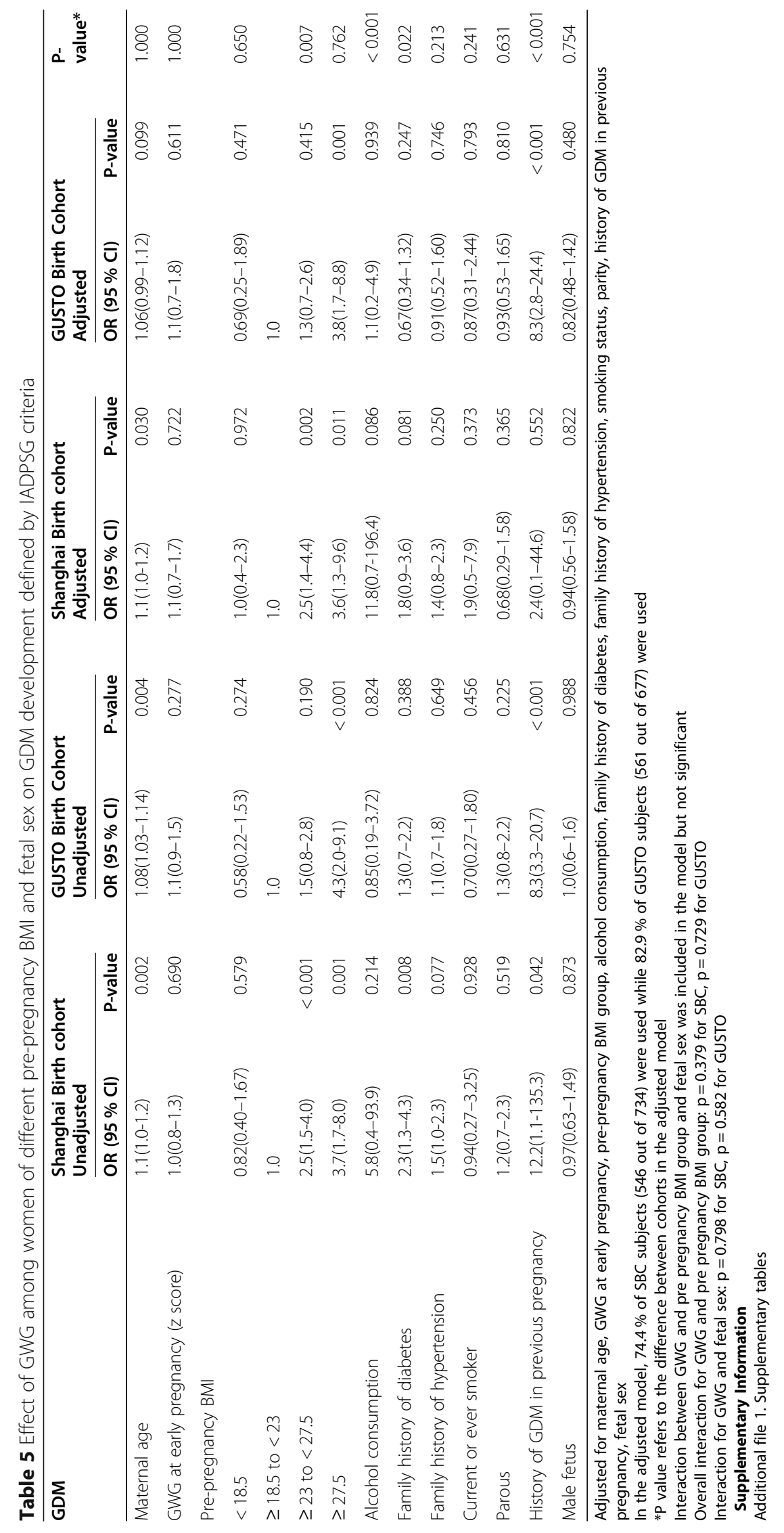




\section{Discussion}

In this study, we compared risk factors of GDM in two Chinese cohorts in Shanghai and Singapore. To the best of our knowledge, this is the first study comparing risk factors of GDM in ethnic Chinese living in different geographical locations. The study findings will primarily be discussed in relation to IADPSG criteria.

We found maternal age and pre-pregnancy BMI as common associated factors of GDM diagnosed by WHO 1999 and IADPSG criteria in both cohorts. Family history of diabetes and being overweight were associated with higher odds of GDM diagnosed by IADPSG criteria in SBC than in GUSTO.

Maternal age is a well-documented risk factor of GDM. In a meta-analysis involving 24 studies and over 120 million participants, GDM risk was demonstrated to increase linearly with age [24]. The relative risk of GDM in an Asian population was estimated to increase by $13 \%$ for every year increase in maternal age over 18 years. Another study of pregnant women from 18 cities in China also found advanced maternal age to be a strong predictor of GDM risk [25]. This could be attributed to an increase in dysfunctional preadipocytes and ectopic fat redistribution with aging which may cause lipotoxicity with the release of proinflammatory cytokines and chemokines disrupting insulin signaling [26, 27].

As expected, higher pre-pregnancy BMI was associated with increased odds of GDM in both cohorts. A metaanalysis of 70 studies involving over 600,000 women showed that each $1 \mathrm{~kg} / \mathrm{m}^{2}$ increase in BMI is linked to a $0.92 \%$ increase in GDM prevalence [28]. Similar to aging, obesity is associated with insulin resistance, ectopic fat accumulation and chronic inflammation as adipocytes release proinflammatory cytokines and chemokines [29]. Further analysis by classifying pre-pregnancy BMI into categories defined for Asian metabolic risk showed that BMI $\geq 27.5 \mathrm{~kg} / \mathrm{m}^{2}$ (obese) was associated with increased odds of GDM [30]. Studies have shown that GDM risk increases linearly with pre-pregnancy BMI [11, 28]. A study of Arab women found a significant association between obesity (prepregnancy BMI $\geq 30 \mathrm{~kg} / \mathrm{m}^{2}$ ) and GDM [31]. Tsiotra et al. reported that obese women had higher levels of circulating adipokines such as chemerin and leptin that may be responsible for inflammation and insulin resistance [32].

Family history of diabetes was associated with significantly higher odds of GDM in the SBC. A metaanalysis involving 84 studies in Asia also found a significant positive association between family history of diabetes and GDM [17]. This may be explained by genetic predisposition as pancreatic islet $\beta$-cell function and/or abnormalities can be inherited through single nucleotide polymorphisms (SNPs) in genes linked to insulin signaling or secretion [33]. Although the prevalence of diabetes in family members was lower in SBC than GUSTO, the higher odds of association with GDM in the SBC may be due to several reasons; genetic differences such as the rs10229583 gene locus polymorphism near PAX4 gene that is responsible for the development of pancreatic $\beta$ cells was implicated in earlier age of diagnosis of type 2 diabetes mellitus in Chinese population in Shanghai and Hong Kong but the effect was less prominent in Singapore Chinese [34]. The risk allele frequency of most SNPs responsible for type 2 diabetes mellitus was also lower in East Asians as compared to South Asians, suggesting ethnic differences even within the Asian population [35].

We did not observe any significant association between GWG in early pregnancy and risk of GDM in the two cohorts. This is supported by Ruhstaller et al. who also reported no association between GDM and weight gain during the first 20 weeks of pregnancy with adjustment for pre-pregnancy BMI [36]. Interestingly, GWG velocity in early pregnancy was associated with significantly higher odds of GDM in GUSTO cohort than in SBC using the 1999 WHO criteria. A possible reason could be due to modulation of GDM risk by genetic variants in fat mass and obesity associated gene such rs1121980 that has been reported to lower the risk of GDM in Chinese in China while not affecting the risk of type 2 diabetes in Singaporean Chinese [37, 38]. Hence differences in genetic make-up may have modulated the impact of GWG on GDM risk in SBC and GUSTO.

Epigenetic changes induced by lifestyle may also explain the difference in risk between the two cohorts. Poorer sleep quality alters DNA methylation in adipose tissues, resulting in higher fat accumulation [39] and risk of GDM [40]. Studies utilizing the Pittsburgh Sleep Quality Index showed that Singaporeans had worse sleep quality with mean score of 5.08 to 5.51 [41] as compared to Shanghai residents with a mean score of 3.69 [42]. A low consumption of folate, a methyl donor, is also linked to obesity and insulin resistance [43]. Chinese women from Singapore had lower plasma folate concentration than those from Shanghai $[44,45]$.

We observed that being overweight was also associated with higher odds of GDM in SBC as compared to GUSTO. This may be due to lifestyle differences. For example, participants from China and Singapore have different dietary patterns which may have affected risk of developing GDM. A study from China reported that the dietary patterns of pregnant women can be classified into Western (fried/baked food, white meat and dairy), traditional (fine grain, red meat, light-coloured vegetables and tubers), mixed (red meat, shrimp or shellfish and edible fungi) and prudent (deep-sea fish and darkcoloured vegetables) where Western and traditional 
patterns increased the risk of GDM [46]. Conversely, a study from Singapore reported that the dietary patterns of pregnant women can be classified into vegetable-fruitrice-based, seafood-noodle-based and pasta-cheeseprocessed-meat where a seafood-noodle-based diet reduced the risk of GDM [47]. In addition, women in China tend to have lower levels of physical activity during pregnancy due to traditional customs where pregnant women are regarded as vulnerable which may have increased the risk of GDM in high-risk women [48].

We also did not observe any differences in odds of GDM between Singaporean citizens and Chinese immigrants from the GUSTO cohort, suggesting that environmental factors play an important role in the development of GDM.

While studies reported higher risks of preterm [49], macrosomia [8] and high birthweight [50] births in GDM, we did not observe these associations in SBC and GUSTO cohorts. This may be explained by effective dietary interventions as women in both cohorts attended prenatal care in high-quality tertiary care centers. Vally et al. showed that GDM mothers with well-controlled diet and glycemia did not have an increased risk of macrosomia [51]. A meta-analysis of studies on Chinese women found that low GI or fiber-enriched diets reduced the risk of preterm births [52].

In this study, we compared 2 different diagnostic criteria of GDM. The IADPSG criteria detects more GDM cases as compared to other criteria [53]. The WHO 1999 criteria might miss GDM cases with elevated fasting glucose concentrations [54].

GDM is known to be a heterogeneous condition and the two different diagnostic criteria probably identify different subtypes of GDM. Supporting evidence on GDM subtypes is provided by the observation of different clinical outcomes associated with elevated fasting and postprandial glucose levels [55]. Women with elevated fasting and normal postprandial values had a higher risk of having large for gestational age babies while women with normal fasting and elevated postprandial values had a higher risk of preterm delivery and gestational hypertension as compared to women without GDM [55].

Strengths of the study include extensive data collection and regular follow up of the subjects in both studies. This is the first study comparing GDM prevalence and risk factors in two cohorts of Chinese women from different countries, namely China and Singapore, using two GDM diagnostic criteria. It is well-known that global differences in GDM prevalence exist due to differences in factors such as diagnostic criteria, ethnicity, lifestyle, and environmental factors. This novel study helps to elucidate if diagnostic criteria or lifestyle differences account for the differences in GDM rates in Chinese people. A limitation of the study is the absence of collection of blood glucose data at the $1 \mathrm{~h}$ timepoint in GUSTO which may have contributed to the lower rates of GDM using the IADPSG criteria and misclassification of some women with GDM as non-GDM, hence diluting the observed risks [56]. Nevertheless, we observed similar findings such as pre-pregnancy BMI being associated with increased odds of GDM using both the WHO 1999 and IADPSG criteria. Another limitation is the inability to assess nutritional aspects and environmental factors such as air pollution which may have explained the differences in risk factors and prevalence of GDM in SBC and GUSTO. We also relied on self-reported pre-pregnancy body weight in this study which is subjected to recall bias.

The findings of the study help to provide different clinical recommendations for GDM prevention in Chinese women from China and Singapore. Women who are intending to start a family can be advised to conceive at a younger age and to control their pre-pregnancy weight. Native Chinese women residing in China who have family history of diabetes and/or are overweight can also be identified as a high-risk group and followed more closely throughout their pregnancy for timely interventions against GDM.

\section{Conclusions}

In conclusion, we observed some differential risk factors of GDM among ethnic Chinese women living in Shanghai and Singapore. These findings might be due to heterogeneity of GDM reflected in diagnostic criteria as well as in unmeasured genetic, lifestyle and environmental factors.

\section{Abbreviations}

BMI: Body mass index; DoHaD: Developmental Origins of Health and Disease; FG: Fasting glucose; GDM: Gestational diabetes mellitus; GUSTO: Growing Up in Singapore Towards healthy Outcomes; GWG: Gestational weight gain; IADPSG: International Association of Diabetes and Pregnancy Groups; OGTT: Oral glucose tolerance test; PG: Plasma glucose; SBC: Shanghai Birth Cohort; SNPs: Single nucleotide polymorphisms

\section{Supplementary Information}

The online version contains supplementary material available at https://doi. org/10.1186/s12884-021-04036-5.

\section{Additional file 1. Supplementary tables.}

\section{Acknowledgements}

We thank the GUSTO study group and all clinical and home-visit staff involved. The voluntary participation of all subjects is greatly appreciated. We appreciate the statistical advice provided by Dr. Chan Yiong Huak. The GUSTO study group includes Allan Sheppard, Amutha Chinnadurai, Anne Eng Neo Goh, Anne Rifkin-Graboi, Anqi Qiu, Arijit Biswas, Bee Wah Lee, Birit Froukje Philipp Broekman, Boon Long Quah, Chai Kiat Chng, Cheryl Shufen Ngo, Choon Looi Bong, Christiani Jeyakumar Henry, Daniel Yam Thiam Goh, Doris Ngiuk Lan Loh, Fabian Kok Peng Yap, George Seow Heong Yeo, Helen Yu Chen, Hugo P S van Bever, Iliana Magiati, Inez Bik Yun Wong, Ivy Yee-Man Lau, Jeevesh Kapur, Jenny L. Richmond, Jerry Kok Yen Chan, Joanna Dawn Holbrook, Joshua J. Gooley, Keith M. Godfrey, Kenneth Yung Chiang Kwek, Kok Hian Tan, Krishnamoorthy Naiduvaje, Leher Singh, Lin Lin Su, Lourdes Mary Daniel, Lynette Pei-Chi Shek, Marielle V. Fortier, Mark Hanson, Mary Foong-Fong Chong, Mary Rauff, Mei Chien Chua, Michael J. Meaney, Mya Thway Tint, Neerja Karnani, Ngee Lek, Oon Hoe Teoh, P. C. Wong, Peter David Gluckman, Pratibha Keshav Agarwal, Rob Martinus van Dam, Salome A. Rebello, Seang Mei Saw, Shang Chee Chong, Shirong Cai, Shu-E Soh, Sok Bee Lim, Stephen Chin-Ying Hsu, Victor Samuel Rajadurai, Walter Stunkel, Wee 
Meng Han, Wei Wei Pang, Yap Seng Chong, Yin Bun Cheung, Yiong Huak Chan and Yung Seng Lee.

\section{Authors' contributions}

Loo EX, Eriksson JG and Zhang J contributed to conception, design, analysis, interpretation of data, drafting and critical review of the manuscript. Yap QV and Lau HX contributed to analysis, interpretation of data and drafting of manuscript. Zhang Y, Yu G, Soh SE, Loy SL, SY Chan, LPC Shek, Luo ZC, Yap $\mathrm{F}$, Tan KH, Chong YS contributed to study design, data acquisition and critical review of manuscript. All authors approved the final version of the manuscript.

\section{Funding}

This research is supported by the Singapore National Research Foundation under its Translational and Clinical Research (TCR) Flagship Program and administered by the Singapore Ministry of Health's National Medical Research Council (NMRC), Singapore-NMRC/TCR/004-NUS/2008; NMRC/TCR/ 012-NUHS/ 2014. Additional funding is provided by the Singapore Institute for Clinical Sciences, Agency for Science Technology and Research (A*STAR), Singapore. The Shanghai Birth Cohort was partly supported by the Shanghai Municipal Health Commission (GWIII-26.1, GWIV-26.1, 2020CXJQ01). The study sponsors had no involvement in the research design, data collection, interpretation of the data, or publication.

\section{Availability of data and materials}

The datasets used and/or analysed during the current study are available from the corresponding author on reasonable request.

\section{Declarations}

\section{Ethics approval and consent to participate}

The study protocol of SBC was approved by the ethics committee of Shanghai Xinhua Hospital (XHEC-C-2013-001, approved on 7 January 2013) and all participating hospitals. The study protocol of GUSTO was approved by the ethics committees of the hospitals involved: SingHealth Centralized Institutional Review Board (2018/2767, approved on 2 March 2019) and the National Healthcare Group Domain Specific Review Board (D/2009/021, approved on 26 February 2009) in Singapore. All methods were performed in accordance with the approved guidelines and regulations. All participants gave written informed consent.

\section{Consent for publication}

Not applicable.

\section{Competing interests}

Shek LP has received reimbursement for speaking at conferences sponsored by Danone and Nestle and consulting for Mead Johnson and Nestle. Chan SY and Chong YS is part of an academic consortium that has received research funding from Abbot Nutrition, Nestle SA and Danone, and are coinventors on patent filings by Nestlé S.A. Shek LP has received research funding from Danone. Chan SY has received reimbursement and honoraria into her research funds from Nestlé S.A. for a half-day consultancy and for speaking at a conference. All other authors declare no conflict of interest.

\section{Author details}

${ }^{1}$ Singapore Institute for Clinical Sciences (SICS), Agency for Science, Technology and Research (A*STAR), 30 Medical Drive, Singapore 117609, Singapore. ${ }^{2}$ Department of Paediatrics, Yong Loo Lin School of Medicine, National University of Singapore, Singapore, Singapore. ${ }^{3}$ Ministry of Education and Shanghai Key Laboratory of Children's Environmental Health, Xinhua Hospital, Shanghai Jiao Tong University School of Medicine, Shanghai, China. ${ }^{4}$ School of Public Health, Shanghai Jiao Tong University, Shanghai, China. ${ }^{5}$ Department of Biostatistics, Yong Loo Lin School of Medicine, National University of Singapore, Singapore, Singapore. ${ }^{6}$ Department of Reproductive Medicine, KK Women's and Children's Hospital, Singapore, Singapore. ${ }^{7}$ Duke-NUS Medical School, Singapore, Singapore. ${ }^{8}$ Department of Obstetrics \& Gynaecology and Human Potential Translational Research Programme, Yong Loo Lin School of Medicine, National University of Singapore and National University Health System, Singapore, Singapore. ${ }^{9}$ Department of Obstetrics and Gynecology, Lunenfeld-Tanenbaum Research Institute, Mount Sinai Hospital, University of Toronto, Toronto M5G 1X5,
Canada. ${ }^{10}$ Department of Paediatrics, KK Women's and Children's Hospital, Singapore, Singapore. "'Lee Kong Chian School of Medicine, Nanyang Technological University, Singapore, Singapore. ${ }^{12}$ Department of Maternal Fetal Medicine, KK Women's and Children's Hospital, Singapore, Singapore. ${ }^{13}$ School of Public Health, Guilin Medical College, Guilin, Guangxi, China. ${ }^{14}$ Folkhälsan Research Center, Helsinki, Finland. ${ }^{15}$ Department of General Practice and Primary Health Care, University of Helsinki, Helsinki, Finland.

Received: 29 January 2021 Accepted: 2 August 2021

Published online: 18 August 2021

\section{References}

1. Waterland RA, Michels KB. Epigenetic epidemiology of the developmental origins hypothesis. Annu Rev Nutr. 2007;27(1):363-88. https://doi.org/10.114 6/annurev.nutr.27.061406.093705.

2. Buchanan TA, Xiang AH. Gestational diabetes mellitus. J Clin Invest. 2005; 115(3):485-91. https://doi.org/10.1172/JCI200524531.

3. Cho N, Shaw J, Karuranga S, Huang Y, da Rocha FJ, Ohlrogge A, et al. IDF diabetes atlas: global estimates of diabetes prevalence for 2017 and projections for 2045. Diabetes Res Clin Pract. 2018;138:271-81. https://doi. org/10.1016/j.diabres.2018.02.023

4. National Diabetes Data Group. Classification and diagnosis of diabetes mellitus and other categories of glucose intolerance. Diabetes. 1979;28(12): 1039-57. https://doi.org/10.2337/diab.28.12.1039.

5. Kim C, Newton KM, Knopp RH. Gestational diabetes and the incidence of type 2 diabetes: a systematic review. Diabetes Care. 2002;25(10):1862-8. https://doi.org/10.2337/diacare.25.10.1862.

6. Kramer CK, Campbell S, Retnakaran R. Gestational diabetes and the risk of cardiovascular disease in women: a systematic review and meta-analysis. Diabetologia. 2019;62(6):905-14. https://doi.org/10.1007/s00125-019-4840-2.

7. Beharier O, Shoham-Vardi I, Pariente G, Sergienko R, Kessous R, Baumfeld Y, et al. Gestational diabetes mellitus is a significant risk factor for long-term maternal renal disease. J Clin Endocrinol Metab. 2015;100(4):1412-6. https:// doi.org/10.1210/jc.2014-4474

8. Kamana K, Shakya S, Zhang H. Gestational diabetes mellitus and macrosomia: a literature review. Ann Nutr Metab. 2015;66(Suppl. 2):14-20.

9. Elliott HR, Sharp GC, Relton CL, Lawlor DA. Epigenetics and gestational diabetes: a review of epigenetic epidemiology studies and their use to explore epigenetic mediation and improve prediction. Diabetologia. 2019;62:2171-8

10. Teh WT, Teede HJ, Paul E, Harrison CL, Wallace EM, Allan C. Risk factors for gestational diabetes mellitus: implications for the application of screening guidelines. Aust N Z J Obstet Gynaecol. 2011;51(1):26-30. https://doi.org/1 0.1111/j.1479-828X.2011.01292.x.

11. Chu SY, Callaghan WM, Kim SY, Schmid CH, Lau J, England LJ, et al. Maternal obesity and risk of gestational diabetes mellitus. Diabetes Care. 2007;30(8):2070-6. https://doi.org/10.2337/dc06-2559a.

12. Hantoushzadeh S, Sheikh M, Bosaghzadeh Z, Ghotbizadeh F, Tarafdari A Panahi $Z$, et al. The impact of gestational weight gain in different trimesters of pregnancy on glucose challenge test and gestational diabetes. Postgrad Med J. 2016;92(1091):520-4. https://doi.org/10.1136/ postgradmedj-2015-133816.

13. Hedderson MM, Gunderson EP, Ferrara A. Gestational weight gain and risk of gestational diabetes mellitus. Obstet Gynecol. 2010;115(3):597-604. https://doi.org/10.1097/AOG.0b013e3181cfce4f.

14. Solomon CG, Willett WC, Carey VJ, Rich-Edwards J, Hunter DJ, Colditz GA, et al. A prospective study of pregravid determinants of gestational diabetes mellitus. JAMA. 1997;278(13):1078-83. https://doi.org/10.1001/jama.1997.03 550130052036.

15. Zhang C, Ning Y. Effect of dietary and lifestyle factors on the risk of gestational diabetes: review of epidemiologic evidence. Am J Clin Nutr. 2011;94(suppl_6):1975S-9S.

16. Eades CE, Cameron DM, Evans JM. Prevalence of gestational diabetes mellitus in Europe: a meta-analysis. Diabetes Res Clin Pract. 2017;129:173-81. https://doi.org/10.1016/j.diabres.2017.03.030.

17. Lee KW, Ching SM, Ramachandran V, Yee A, Hoo FK, Chia YC, et al. Prevalence and risk factors of gestational diabetes mellitus in Asia: a systematic review and meta-analysis. BMC Pregnancy Childbirth. 2018;18(1): 494. https://doi.org/10.1186/s12884-018-2131-4.

18. Yew $T$, Khoo C, Thai A, Kale A, Yong E, Tai E. The prevalence of gestational diabetes mellitus among Asian females is lower using the new 2013 World 
Health Organization diagnostic criteria. Endocr Pract. 2014;20(10):1064-9. https://doi.org/10.4158/EP14028.OR.

19. Zheng T, Ye W, Wang X, Li X, Zhang J, Little J, et al. A simple model to predict risk of gestational diabetes mellitus from 8 to 20 weeks of gestation in Chinese women. BMC Pregnancy Childbirth. 2019;19(1):252. https://doi. org/10.1186/s12884-019-2374-8

20. Zhang J, Tian Y, Wang W, Ouyang F, Xu J, Yu X, et al. Cohort profile: the Shanghai birth cohort. Int J Epidemiol. 2019;48(1):21-21g.

21. Soh S-E, Tint MT, Gluckman PD, Godfrey KM, Rifkin-Graboi A, Chan YH, et al. Cohort profile: growing up in Singapore towards healthy outcomes (GUSTO) birth cohort study. Int J Epidemiol. 2014;43(5):1401-9. https://doi. org/10.1093/ije/dyt125.

22. WHO Expert Consultation. Appropriate body-mass index for Asian populations and its implications for policy and intervention strategies. Lancet. 2004:363(9403):157-63.

23. Mikolajczyk RT, Zhang J, Betran AP, Souza JP, Mori R, Gülmezoglu $A M$, et al. A global reference for fetal-weight and birthweight percentiles. Lancet. 2011;377(9780):1855-61. https://doi.org/10.1016/ S0140-6736(11)60364-4.

24. Li Y, Ren X, He L, Li J, Zhang S, Chen W. Maternal age and the risk of gestational diabetes mellitus: a systematic review and meta-analysis of over 120 million participants. Diabetes Res Clin Pract. 2020;162:108044. https:// doi.org/10.1016/j.diabres.2020.108044.

25. Yang H, Wei Y, Gao X, Xu X, Fan L, He J, et al. Risk factors for gestational diabetes mellitus in Chinese women - a prospective study of 16286 pregnant women in China. Diabet Med. 2009;26(11):1099-104. https://doi. org/10.1111/j.1464-5491.2009.02845.x.

26. Sepe A, Tchkonia T, Thomou T, Zamboni M, Kirkland JL. Aging and regional differences in fat cell progenitors - a mini-review. Gerontology. 2011;57(1): 66-75. https://doi.org/10.1159/000279755

27. Snel M, Jonker JT, Schoones J, Lamb H, de Roos A, Pijl H, et al. Ectopic fat and insulin resistance: pathophysiology and effect of diet and lifestyle interventions. Int J Endocrinol. 2012;2012:1-18. https://doi.org/10.1155/2012/ 983814

28. Torloni M, Betran A, Horta B, Nakamura M, Atallah A, Moron A, et al. Prepregnancy BMl and the risk of gestational diabetes: a systematic review of the literature with meta-analysis. Obes Rev. 2009;10(2):194-203. https:// doi.org/10.1111/j.1467-789X.2008.00541.x.

29. Lee H, Lee IS, Choue R. Obesity, inflammation and diet. Pediatr Gastroenterol Hepatol Nutr. 2013;16(3):143-52. https://doi.org/10.5223/ pghn.2013.16.3.143.

30. Shiwaku K, Anuurad E, Enkhmaa B, Kitajima K, Yamane Y. Appropriate BMI for Asian populations. Lancet. 2004;363(9414):1077. https://doi.org/10.1016/ S0140-6736(04)15856-X.

31. Shaukat S, Nur U. Effect of prepregnancy maternal BMI on adverse pregnancy and neonatal outcomes: results from a retrospective cohort study of a multiethnic population in Qatar. BMJ Open. 2019;9(9):e029757. https://doi.org/10.1136/bmjopen-2019-029757.

32. Tsiotra PC, Halvatsiotis P, Patsouras K, Maratou E, Salamalekis G, Raptis SA, et al. Circulating adipokines and mRNA expression in adipose tissue and the placenta in women with gestational diabetes mellitus. Peptides. 2018;101: 157-66. https://doi.org/10.1016/j.peptides.2018.01.005.

33. Zhang C, Bao W, Rong Y, Yang H, Bowers K, Yeung E, et al. Genetic variants and the risk of gestational diabetes mellitus: a systematic review. Hum Reprod Update. 2013;19(4):376-90. https://doi.org/10.1093/ humupd/dmt013.

34. Ma R, Hu C, Tam C, Zhang R, Kwan P, Leung T, et al. Genome-wide association study in a Chinese population identifies a susceptibility locus for type 2 diabetes at 7q32 near PAX4. Diabetologia. 2013;56(6):1291-305. https://doi.org/10.1007/s00125-013-2874-4

35. Qi Q, Wang X, Strizich G, Wang T. Genetic determinants of type 2 diabetes in Asians. Int J Diabetol Vasc Dis Res. 2015;2015(Suppl 1):1-9.

36. Ruhstaller K, Bastek J, Thomas A, McElrath T, Parry S, Durnwald C. Initial BMI, not early weight gain, increases the risk of GDM. Am J Obstet Gynecol. 2015;212(1):S396

37. Cao M, Zhang L, Chen T, Shi A, Xie K, Li Z, et al. Genetic susceptibility to gestational diabetes mellitus in a Chinese population. Front Endocrinol (Lausanne). 2020;11:247.

38. Tan JT, Dorajoo R, Seielstad M, Sim XL, Ong RT-H, Chia KS, et al. FTO variants are associated with obesity in the Chinese and Malay populations in Singapore. Diabetes. 2008;57(10):2851-7. https://doi. org/10.2337/db08-0214.

39. Cedernaes J, Schönke M, Westholm JO, Mi J, Chibalin A, Voisin S, et al. Acute sleep loss results in tissue-specific alterations in genome-wide DNA methylation state and metabolic fuel utilization in humans. Sci Adv. 2018; 4(8):eaar8590.

40. Cai S, Tan S, Gluckman PD, Godfrey KM, Saw S-M, Teoh OH, et al. Sleep quality and nocturnal sleep duration in pregnancy and risk of gestational diabetes mellitus. Sleep. 2017;40(2):zsw058.

41. Dunleavy G, Bajpai R, Comiran Tonon A, Chua AP, Cheung KL, Soh C-K, et al. Examining the factor structure of the Pittsburgh sleep quality index in a multi-ethnic working population in Singapore. Int J Environ Res Public Health. 2019;16(23):4590. https://doi.org/10.3390/ijerph 16234590.

42. Wu W, Jiang $Y$, Wang $N$, Zhu M, Liu X, Jiang F, et al. Sleep quality of Shanghai residents: population-based cross-sectional study. Qual Life Res. 2020;29(4):1055-64. https://doi.org/10.1007/s11136-019-023 71-x.

43. Ling C, Rönn T. Epigenetics in human obesity and type 2 diabetes. Cell Metab. 2019;29(5):1028-44. https://doi.org/10.1016/j.cmet.2019.03. 009.

44. Hughes K, Ong C-N. Homocysteine, folate, vitamin B12, and cardiovascular risk in Indians, Malays, and Chinese in Singapore. J Epidemiol Community Health. 2000;54(1):31-4. https://doi.org/10.1136/jech.54.1.31

45. Hao L, Ma J, Stampfer MJ, Ren A, Tian Y, Tang Y, et al. Geographical, seasonal and gender differences in folate status among Chinese adults. J Nutr. 2003:133(11):3630-5. https://doi.org/10.1093/jn/133.11.3630.

46. Du HY, Jiang H, Karmin O, Chen B, Xu LJ, Liu SP, et al. Association of Dietary Pattern during pregnancy and gestational diabetes mellitus: a prospective cohort study in northern China. Biomed Environ Sci. 2017;30(12):887-97. https://doi.org/10.3967/bes2017.119.

47. de Seymour J, Chia A, Colega M, Jones B, McKenzie E, Shirong C, et al. Maternal dietary patterns and gestational diabetes mellitus in a multi-ethnic Asian cohort: the GUSTO study. Nutrients. 2016;8(9):574.

48. Xiang M, Zhang J, Liang H, Zhang Z, Konishi M, Hu H, et al. Physical activity and dietary intake among Chinese pregnant women: an observational study. BMC Pregnancy Childbirth. 2019;19(1):1-8.

49. Simeonova-Krstevska S, Velkoska Nakova V, Samardziski I, Atanasova Bosku A, Todorovska I, Sima A, et al. Perinatal outcome in gestational diabetes Melitus vs Normoglycemic women. Biomed J Sci Tech Res. 2020;26(2): 19882-8.

50. Yang $Y$, Wang $Z$, Mo M, Muyiduli $X$, Wang $S$, Li M, et al. The association of gestational diabetes mellitus with fetal birth weight. J Diabetes Complicat. 2018;32(7):635-42. https://doi.org/10.1016/j.jdia comp.2018.04.008.

51. Vally F, Presneill J, Cade T. Macrosomia rates in women with diet-controlled gestational diabetes: a retrospective study. J Pregnancy. 2017;2017:1-5. https://doi.org/10.1155/2017/4935397.

52. Wan CS, Nankervis A, Teede $H$, Aroni R. Dietary intervention strategies for ethnic Chinese women with gestational diabetes mellitus: a systematic review and meta-analysis. Nutr Diet. 2019;76(2):211-32. https://doi.org/1 $0.1111 / 1747-0080.12524$

53. Brown FM, Wyckoff J. Application of one-step IADPSG versus two-step diagnostic criteria for gestational diabetes in the real world: impact on health services, clinical care, and outcomes. Curr Diab Rep. 2017;17(10):85. https://doi.org/10.1007/s11892-017-0922-z.

54. Shen S, Lu J, Zhang L, He J, Li W, Chen N, et al. Single fasting plasma glucose versus $75-\mathrm{g}$ oral glucose-tolerance test in prediction of adverse perinatal outcomes: a cohort study. EBioMedicine. 2017;16:284-91. https:// doi.org/10.1016/j.ebiom.2017.01.025.

55. Black MH, Sacks DA, Xiang AH, Lawrence JM. Clinical outcomes of pregnancies complicated by mild gestational diabetes mellitus differ by combinations of abnormal oral glucose tolerance test values. Diabetes Care. 2010;33(12):2524-30. https://doi.org/10.2337/dc10-1445.

56. Chi C, Loy SL, Chan S-Y, Choong C, Cai S, Soh SE, et al. Impact of adopting the 2013 World Health Organization criteria for diagnosis of gestational diabetes in a multi-ethnic Asian cohort: a prospective study. BMC Pregnancy Childbirth. 2018;18(1):69. https://doi.org/10.1186/s12884-018-1707-3.

\section{Publisher's Note}

Springer Nature remains neutral with regard to jurisdictional claims in published maps and institutional affiliations. 